Subscriber access provided by Caltech Library

\title{
Communication
}

\section{A Super-Oxidized Radical Cationic Icosahedral Boron Cluster}

Julia M Stauber, Josef Schwan, Xinglong Zhang, Jonathan Axtell, Dahee Jung, Brendon James McNicholas, Paul H. Oyala, Andrew J. Martinolich, Jay R. Winkler, Kimberly A. See, Thomas Francis Miller, Harry B. Gray, and Alexander M Spokoyny

J. Am. Chem. Soc., Just Accepted Manuscript • DOI: 10.1021/jacs.0c06159 • Publication Date (Web): 09 Jul 2020

Downloaded from pubs.acs.org on July 10, 2020

\section{Just Accepted}

"Just Accepted" manuscripts have been peer-reviewed and accepted for publication. They are posted online prior to technical editing, formatting for publication and author proofing. The American Chemical Society provides "Just Accepted" as a service to the research community to expedite the dissemination of scientific material as soon as possible after acceptance. "Just Accepted" manuscripts appear in full in PDF format accompanied by an HTML abstract. "Just Accepted" manuscripts have been fully peer reviewed, but should not be considered the official version of record. They are citable by the Digital Object Identifier (DOI@). "Just Accepted" is an optional service offered to authors. Therefore, the "Just Accepted" Web site may not include all articles that will be published in the journal. After a manuscript is technically edited and formatted, it will be removed from the "Just Accepted" Web site and published as an ASAP article. Note that technical editing may introduce minor changes to the manuscript text and/or graphics which could affect content, and all legal disclaimers and ethical guidelines that apply to the journal pertain. ACS cannot be held responsible for errors or consequences arising from the use of information contained in these "Just Accepted" manuscripts. 
Polyhedral boron clusters have provided a platform for rich scientific exploration with applications ranging from materials science to medicine. ${ }^{1-10}$ The icosahedral closo- $\left[\mathrm{B}_{12} \mathrm{H}_{12}\right]^{2-}$ dianion $^{11}$ has been a focus of investigation on account of its high stability, three-dimensional delocalized bonding, resistance to harsh chemical environments, and ease of electrophilic $\mathrm{B}-\mathrm{H}$ substitution. ${ }^{12}$ Work describing the oneelectron oxidation of $\left[\mathrm{B}_{12} \mathrm{H}_{12}\right]^{2-}$, however, displayed cluster decomposition and dimerization, revealing the oxidative instability of this species. ${ }^{13}$ These findings were rationalized by the Wade-Mingos $2 n+2$ ( $n=$ number of vertices) electroncounting rules, which predict the structures of polyhedral molecules based on the number of skeletal electron pairs (Figure 1A). ${ }^{14,15}$ However, despite these predictions, perfunctionalization of closo- $\left[\mathrm{B}_{12} \mathrm{H}_{12}\right]^{2-}$ can engender reversible redox chemistry, which provides ready access to neutral, hypercloso- $\mathrm{B}_{12} \mathrm{R}_{12}$ derivatives (Figure 1B). ${ }^{12,16-20}$ Stabilization of these species is attributed to steric protection of the cluster-confined frontier orbitals by bulky substituents, and the electron-donor effects of supporting groups that supply extra electron density to the electron-deficient $\mathrm{B}_{12}$ cores. ${ }^{2,12}$ To our knowledge, however, dodecaborane clusters oxidized beyond the hypercloso state have never been reported. This redox boundary poses critical questions concerning the oxidation limit of icosahedral boron clusters, which is not only of fundamental interest, but could also have implications in the use of $\mathrm{B}_{12}$-based materials for energy storage and other applications. ${ }^{2,21-23}$

As previously established, $, 2,12,20,21,24,25$ the redox potential of alkoxy and benzyloxy-substituted $\mathrm{B}_{12}$ clusters $\left(\left[\mathrm{B}_{12}(\mathrm{OR})_{12}\right]\right)$ can be rationally tuned as a function of their substituents by greater than $1 \mathrm{~V}$ for the same redox event. With this in mind,
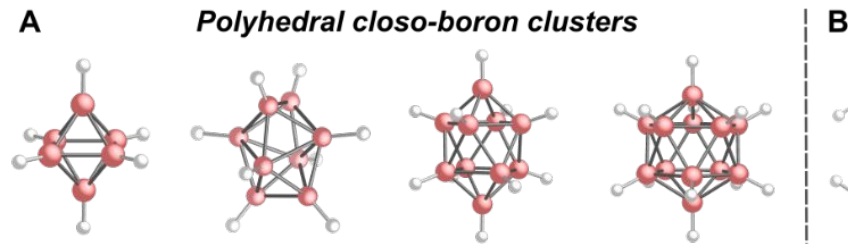

$\left[\mathrm{B}_{7} \mathrm{H}_{7}\right]^{2-}$

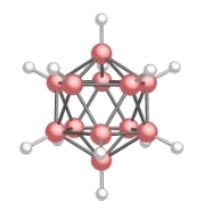

$\left[\mathrm{B}_{12} \mathrm{H}_{12}\right]^{2-}$
B Redox-active closo-dodecaborate clusters

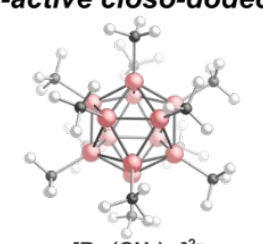

$\left[\mathrm{B}_{12}\left(\mathrm{CH}_{3}\right)_{12}\right]^{2-}$

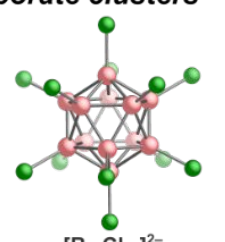

$\left[\mathrm{B}_{12} \mathrm{Cl}_{12}\right]^{2-}$

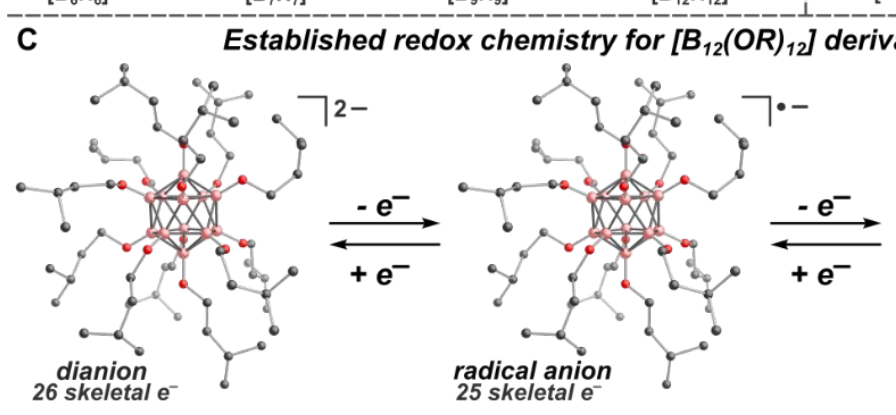

$\left[\mathrm{B}_{12}(\mathrm{OH})_{12}\right]^{2-}$

\section{vatives}
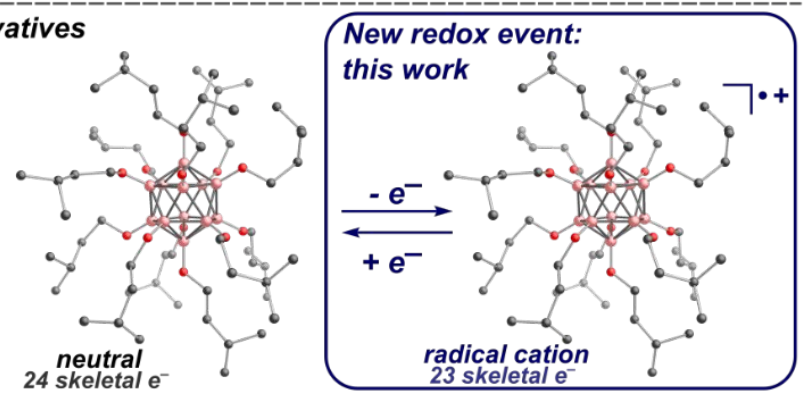

Figure 1. A: Structures of polyhedral closo-boron clusters as predicted by the Wade-Mingos electron-counting rules. ${ }^{14,15} \mathrm{~B}$ : Examples of redox-active, perfunctionalized closo-dodecaborate clusters $\left(\left[\mathrm{B}_{12}(\mathrm{OH})_{12}\right]^{2-},{ }^{19}\left[\mathrm{~B}_{12}\left(\mathrm{CH}_{3}\right)_{12}\right]^{2-18}\right.$ and $\left.\left[\mathrm{B}_{12} \mathrm{Cl}_{12}\right]^{2-16}\right)$. C: Established redox chemistry for alkoxy and benzyloxysubstituted $\mathrm{B}_{12}$ clusters, ${ }^{2,12,20,21,24,25}$ and this work, which introduces a third, reversible redox event for the $\mathrm{B}_{12}(\mathrm{O}-3 \text {-methylbutyl })_{12}(\mathbf{1})$ derivative.

stable and isolable monoanionic, hypocloso- $\left[\mathrm{B}_{12} \mathrm{R}_{12}\right]^{--}$, and in addition to the high chemical, electrochemical, and ACS Paragon Plus Environment 
structural stability of icosahedral boron clusters, ${ }^{1,2,5,21,26-28}$ we envisioned we could tune and expand the redox potential window of $\mathrm{B}_{12}(\mathrm{OR})_{12}$ derivatives through judicious selection of the supporting substituents. Surprisingly, during this work, we discovered a previously unrecognized electrochemical event that allowed us to observe the first example of a superoxidized $\mathrm{B}_{12}$-based radical cation at a chemically accessible potential (Figure 1C).

We identified the $\mathrm{B}_{12}(\mathrm{O}-3 \text {-methylbutyl })_{12}$ (1) derivative, originally reported by Hawthorne et al., ${ }^{12}$ as a model cluster for investigation due to the inherent steric protection provided by the bulky alkyl groups, which we predicted would provide extra stability to a highly reactive, cluster-based radical cation. Additionally, the inductive electron-donating nature of the 3methylbutyl groups provides 1 with low potentials for the $[\mathbf{1}]^{2-}$ ${ }^{1-}$ and $[1]^{-/ 0}$ redox couples, ${ }^{20}$ which we anticipated would shift a $[1]^{0 / \cdot+}$ couple to a potential accessible using common chemical oxidants. Here, we report the successful one-electron oxidation of hypercloso-1, yielding the $[1]^{\cdot+}$ radical cation in isolable form. The super-oxidized $[1]^{\circ+}$ species introduces a new redox state of $B_{12}$ clusters previously perceived as inaccessible, and represents the first characterized experimental example of a boron cluster-based three-electron violation of the Wade-Mingos rules.

A

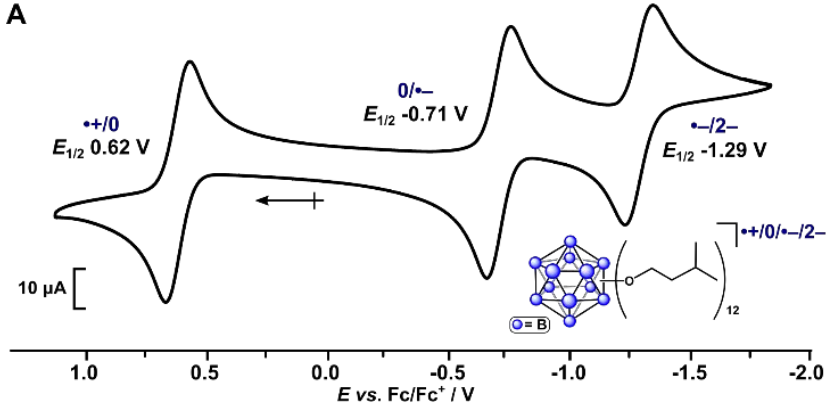

B
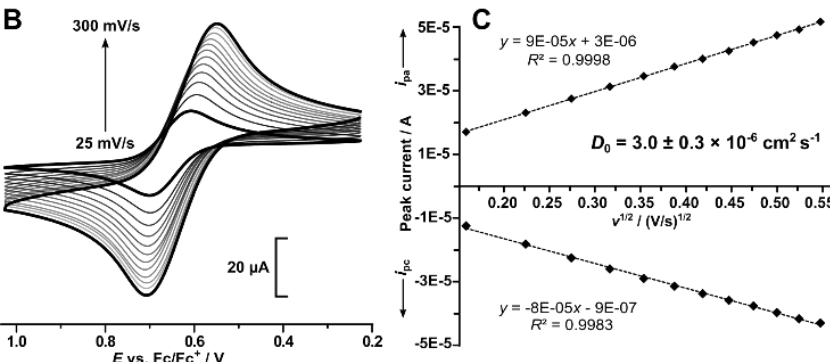

Figure 2. (A) $\mathrm{CV}$ of $1(100 \mathrm{mV} / \mathrm{s})$. (B) $\mathrm{CV}$ of the $[1]^{0 /++}$ redox couple recorded at variable scan rates. (C) Randles-Sevcik plot of the $\mathrm{CV}$ data from (B). A DCM solution of $1(3 \mathrm{mM})$ with $\left[{ }^{n} \mathrm{Bu}_{4} \mathrm{~N}\right]\left[\mathrm{PF}_{6}\right](0.1 \mathrm{M})$ supporting electrolyte was used.

The 1 cluster was synthesized through per- $O$-alkylation of closo- $\left[\mathrm{B}_{12}(\mathrm{OH})_{12}\right]^{2-}$ with 1-bromo-3-methylbutane followed by sequential two-electron chemical oxidation with $\mathrm{FeCl}_{3} \cdot 6 \mathrm{H}_{2} \mathrm{O} \cdot{ }^{12,24}$ Neutral, hypercloso-1 was isolated in pure form as an air-stable solid, and was characterized by ${ }^{1} \mathrm{H}$ and ${ }^{11} \mathrm{~B}$ NMR spectroscopy, electrospray ionization mass spectrometry (ESI-MS(+)), and UV-vis spectroscopy (SI Section S2.1).

We next evaluated the electrochemical properties of 1 by cyclic voltammetry (CV). The CV of 1 (Figure $2 \mathrm{~A}$ ) displays two reversible, one-electron redox events assigned to the $[1]^{2-}$ 1.- $(-1.29 \mathrm{~V})$ and $[1]^{\bullet / 0}(-0.71 \mathrm{~V})$ couples $\left(v s . \mathrm{Fc} / \mathrm{Fc}^{+}\right)$with halfwave potentials $\left(E_{1 / 2}\right)$ that are consistent with those previously reported..$^{20}$ However, anodic scanning past the $[1]^{\bullet / 0}$ couple revealed a third reversible redox event at $E_{1 / 2} 0.62 \mathrm{~V}$, which was not described in the original report. ${ }^{20} \mathrm{We}$ considered this electrochemical event could be attributed to the $[1]^{0 / \cdot+}$ couple, which is the first time to our knowledge that a $0 / \bullet+\mathrm{B}_{12}$-based redox event has been observed for any dodecaborane cluster.

The scan rate dependent behavior of this new redox event indicated a diffusion-controlled reversible electrochemical process as judged by a Randles-Sevcik analysis ${ }^{29}$ (Figure 2B, C) of peak current $\left(i_{\mathrm{p}}\right) v s$. the square root of the scan rate $\left(v^{1 / 2}\right)$. The diffusion coefficient $\left(D_{0}\right)$ determined from this study was calculated as $3.0 \pm 0.3 \times 10^{-6} \mathrm{~cm}^{2} \mathrm{~s}^{-1}$, which is consistent with $D_{0}$ values reported for related $\left[\mathrm{B}_{12}(\mathrm{OR})_{12}\right]$ clusters $^{21}$ and other molecular systems ${ }^{30}$ of comparable size and shape.

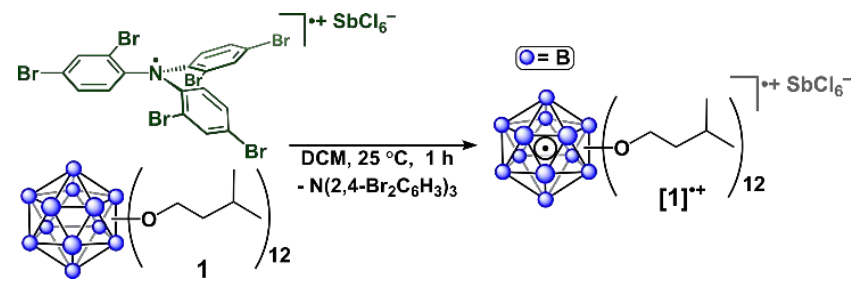

Scheme 1. Protocol for the preparation of $[1]\left[\mathrm{SbCl}_{6}\right]$.

The $\left[\mathrm{N}\left(2,4-\mathrm{Br}_{2} \mathrm{C}_{6} \mathrm{H}_{3}\right)_{3}\right]^{++}$triarylaminium radical $^{31}$ was selected as a suitable reagent to effect the one-electron chemical oxidation of hypercloso-1 due to its appropriate redox potential, ease of preparation, excellent stability, and convenience of handling. ${ }^{32}$ Treatment of 1 with $[\mathrm{N}(2,4-$ $\left.\left.\mathrm{Br}_{2} \mathrm{C}_{6} \mathrm{H}_{3}\right)_{3}\right]\left[\mathrm{SbCl}_{6}\right]$ in dichloromethane elicited a color change from dark yellow to yellow brown immediately upon addition (Scheme 1). After workup, the product of this reaction was analyzed by ${ }^{1} \mathrm{H}$ NMR spectroscopy (SI Figure S7), which revealed the formation of new and broadened resonances consistent with the generation of a paramagnetic species. In line with these data, the reaction product is silent by ${ }^{11} \mathrm{~B} \mathrm{NMR}$ spectroscopy (Figure 3A), which agrees well with the intended one-electron oxidation of the diamagnetic hypercloso-1 cluster and formation of the paramagnetic $[\mathbf{1}]^{\cdot+}$ cation, and suggests the spin density is delocalized throughout the boron atoms of

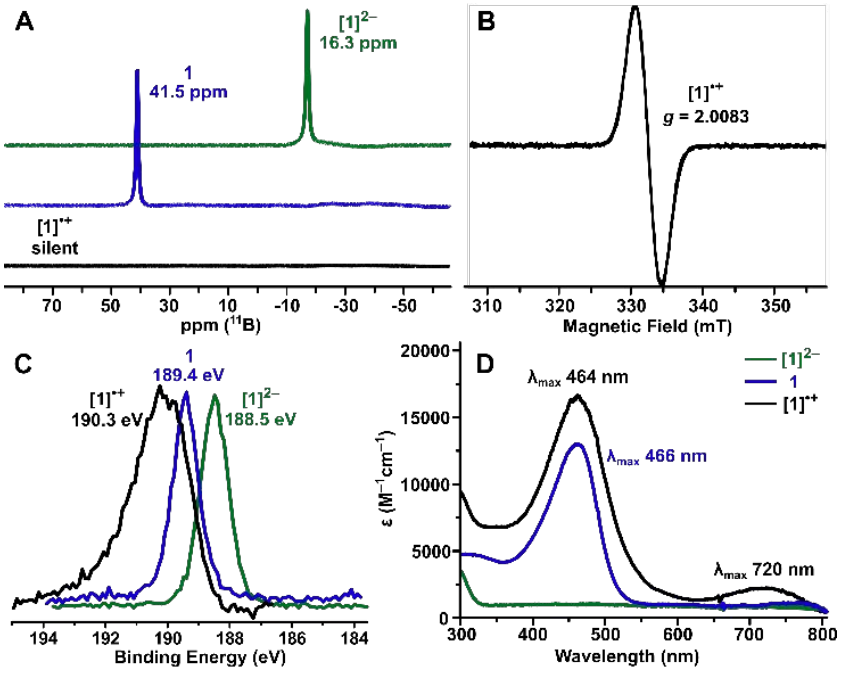

the cluster core.

Figure 3. (A) ${ }^{11} \mathrm{~B}\left\{{ }^{1} \mathrm{H}\right\}$ NMR spectra of $\left[\mathrm{Na}\left(\mathrm{Et}_{2} \mathrm{O}\right)\right]_{2}[\mathbf{1}]$, 1, and $[\mathbf{1}]\left[\mathrm{SbCl}_{6}\right]$. (B) X-band CW-EPR spectrum of in-situ generated [1] ${ }^{++}$. (C) Boron $1 s$ XPS data of $\left[\mathrm{Na}\left(\mathrm{Et}_{2} \mathrm{O}\right)\right]_{2}[\mathbf{1}], \mathbf{1}$, and $[\mathbf{1}]\left[\mathrm{SbCl}_{6}\right]$. (D) UV-vis spectra of $\left[\mathrm{Na}\left(\mathrm{Et}_{2} \mathrm{O}\right)\right]_{2}[\mathbf{1}], \mathbf{1}$, and $[\mathbf{1}]\left[\mathrm{SbCl}_{6}\right]$. 
Electron paramagnetic resonance (EPR) spectroscopy was used to further validate the paramagnetic nature of $[\mathbf{1}]^{++}$. The $\mathrm{X}$-band continuous-wave (CW) EPR spectrum of in-situ generated $\left[\mathbf{1}^{++}\right.$(Figure 3B) displays one relatively broad singlet centered at $g=2.0083$ that is consistent with a doublet state. The broadness of this signal is due to extensive and overlapping hyperfine splitting patterns that result from the delocalization of a single electron across all twelve boron nuclei of the cluster core. ${ }^{17,19}$ The signal broadness and isotropic $g$-factor of this species are consistent with EPR data of hypocloso-dodecaborate radical anion analogues that our group ${ }^{23-25}$ and others ${ }^{16-19}$ have previously reported, and further support the presence of an unpaired electron that is delocalized throughout the $\mathrm{B}_{12}$ core.

Before proceeding with the characterization of $[1]^{++}$, we synthesized the $\operatorname{closo}-[\mathbf{1}]^{2-}$ cluster for its use to benchmark the spectroscopic properties of 3-methylbutoxy-substituted clusters. Closo- $[\mathbf{1}]^{2-}$ was prepared through a two-electron chemical reduction of 1 with $\mathrm{Na} / \mathrm{Hg}$ amalgam in $\mathrm{Et}_{2} \mathrm{O}$, and the $\left[\mathrm{Na}\left(\mathrm{Et}_{2} \mathrm{O}\right)\right]_{2}[\mathbf{1}]$ salt was characterized by UV-vis spectroscopy, XPS, and heteronuclear NMR spectroscopy $\left({ }^{1} \mathrm{H},{ }^{11} \mathrm{~B}\right)$. Efforts to isolate the hypocloso-[1] $]^{-}$cluster in pure form unfortunately have thus far proven unsuccessful due to its rapid disproportionation to $\mathbf{1}$ and $[\mathbf{1}]^{2-}$ upon formation (SI Section S8).

X-ray photoelectron spectroscopy (XPS) has proven to be a valuable tool for assessing the charge state of molecular and extended network boron cluster systems based on predictable trends in boron $1 s$ binding energies. ${ }^{21,23-25}$ The XPS measurements of $[\mathbf{1}]^{++}, \mathbf{1}$, and $[\mathbf{1}]^{2-}$ (Figure $3 \mathrm{C}$ ) feature boron $1 s$ regions that display the presence of intact molecular clusters with increasing binding energies that are consistent with the corresponding increased redox state of the clusters. The highest binding energy was observed for $[1]^{0^{+}}(190.3 \mathrm{eV})$, and suggests that this cluster is the most oxidized of the series, further substantiating the electron-deficient nature of the $\mathrm{B}_{12}$ core, and our formulation of this species as a radical cation. The boron $1 s$ binding energies observed for $\mathbf{1}$ and $[\mathbf{1}]^{2-}$ of 189.4 and $188.5 \mathrm{eV}$, respectively, agree well with the values reported for other hypercloso and closo cluster derivatives. ${ }^{21,23-25}$

As previously reported, sequential oxidation of colorless closo- $\left[\mathrm{B}_{12}(\mathrm{OR})_{12}\right]^{2-}$ species to the hypercloso form leads to the formation of intensely colored solutions marked by diagnostic electronic absorption bands observed by UV-vis spectroscopy. ${ }^{12,20,24,25}$ For the present system, the colorless $\left[\mathrm{Na}\left(\mathrm{Et}_{2} \mathrm{O}\right)\right]_{2}[1]$ salt displayed negligible absorptions across the visible region, while the UV-vis spectrum of 1 exhibits an absorption located at $\lambda_{\max } 466 \mathrm{~nm}$ that is attributed to charge transfer from the peripheral oxygen atoms of the alkoxy substituents to the $\mathrm{B}_{12}$ core., ${ }^{2,12,24,25}$ The $[\mathbf{1}]\left[\mathrm{SbCl}_{6}\right]$ salt displays two major absorptions in the visible region at $\lambda_{\max } 464$ and 720 $\mathrm{nm}$ (Figure 3D). Since the $720 \mathrm{~nm}$ absorption is a diagnostic feature of the radical cationic form, we performed timedependent density functional theory (TD-DFT) calculations (vide infra) on the optimized geometry of $[\mathbf{1}]^{++}$(SI Section S9.2) to investigate the electronic transitions that give rise to this defining absorption.

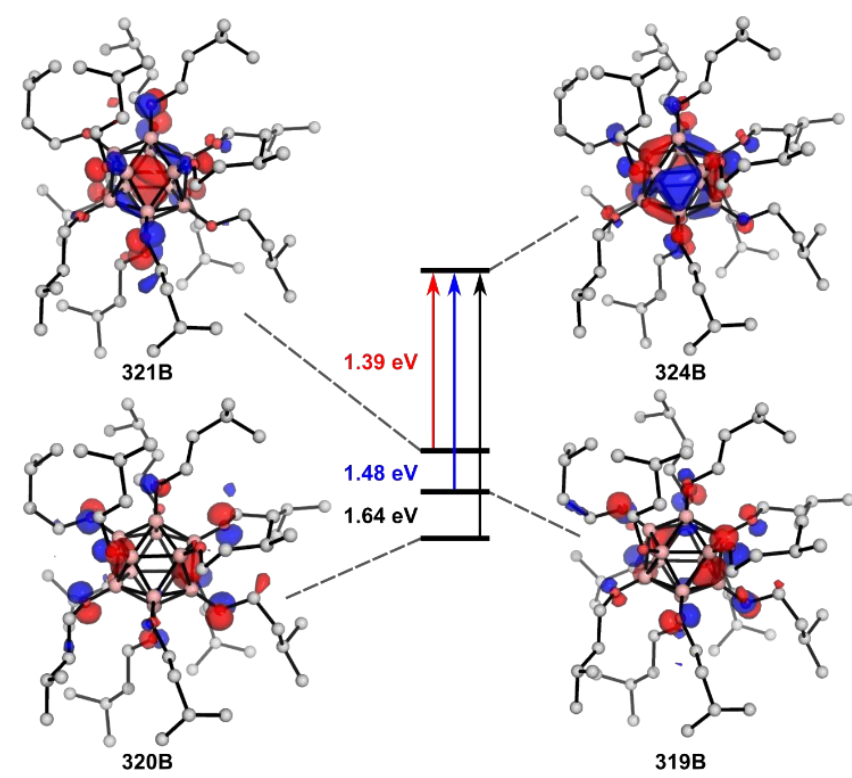

Figure 4. $\beta$-spin molecular orbitals of $[1]^{\cdot+}$ involved in the transitions giving rise to the $720 \mathrm{~nm}$ absorption observed in the UV-vis spectrum (Figure 3D).

The TD-DFT calculations revealed that the $720 \mathrm{~nm}$ absorption is predominantly attributed to excitation of the $\beta$ spin electron from the occupied orbitals (MOs \#319B, 320B, $321 \mathrm{~B})$ to the $\beta$-spin LUMO orbital (\#324B) (Figure 4), which involve charge transfer from the peripheral oxygen atoms of the alkoxy substituents to the $\mathrm{B}_{12}$ cluster core. These results together with the spin density plot calculated for $[\mathbf{1}]^{++}$(Figure

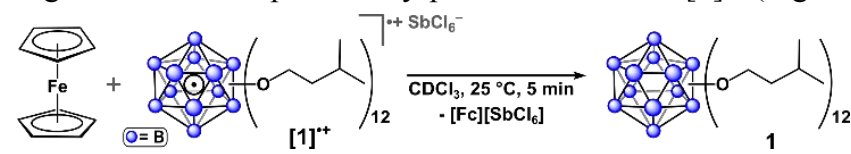
S30) indicate that the unpaired electron is delocalized over both the electronegative oxygen atoms and the $\mathrm{B}_{12}$ cage.

Scheme 2. Protocol for the reduction of $[1]\left[\mathrm{SbCl}_{6}\right]$ with ferrocene.

Having established the electrochemical reversibility of the $[1]^{0 / \cdot+}$ redox event, we next assessed its chemical reversibility through one-electron reduction of $[\mathbf{1}]\left[\mathrm{SbCl}_{6}\right]$ with ferrocene $(\mathrm{Fc})$ (Scheme 2). Treatment of $[\mathbf{1}]\left[\mathrm{SbCl}_{6}\right]$ with ferrocene resulted in the rapid generation of $\mathbf{1}$ as assayed by ${ }^{1} \mathrm{H}$ and ${ }^{11} \mathrm{~B}$ NMR spectroscopic analyses of the crude reaction mixture (SI Section S6). The clean chemical reversibility of this oneelectron redox process is indicative that the $\mathrm{B}_{12}(\mathrm{O}-3-$ methylbutyl $)_{12}$ architecture maintained its integrity during the course of the oxidation of 1 to [1] $]^{++}$without suffering any deleterious processes such as degradation or loss of alkoxy substituents, and that the $[\mathbf{1}]^{++}$species is in fact a well-defined and intact cluster.

This work presents the reversible electrochemical and chemical oxidation of hypercloso-1, to provide the first example of a super-oxidized, spin delocalized $\mathrm{B}_{12}$-based radical cation whose identity was substantiated by various spectroscopic characterization. The discovery of $[1]^{++}$provides an entry point into a new class of stable $\mathrm{B}_{12}$ clusters that could potentially serve as extremely potent chemical oxidants, and whose reactivity has yet to be fully leveraged. The $[1]^{++}$ 
species also poses interesting questions regarding the true oxidation limits of icosahedral boron clusters and contributes to a body of research interested in pushing the redox boundaries of archetypal molecular systems and the stabilization of unusual electronic states. ${ }^{33-45}$

\section{ASSOCIATED CONTENT}

The Supporting Information including experimental procedures and characterization data for all new compounds is available free of charge via the Internet at http://pubs.acs.org.

\section{AUTHOR INFORMATION}

\section{Corresponding Authors}

Alexander M. Spokoyny - Department of Chemistry and Biochemistry, University of California, Los Angeles, 607 Charles E. Young Dr. E., Los Angeles, CA 90095; California NanoSystems Institute, University of California, Los Angeles 570 Westwood Plaza, Los Angeles, CA 90095

orcid.org/0000-0002-5683-6240

Email: spokoyny@chem.ucla.edu

Thomas F. Miller III - Division of Chemistry and Chemical Engineering, California Institute of Technology, 1200 East California Boulevard, Pasadena, CA 91125 orcid.org/0000-0002-4453-9716

Email:tfm@caltech.edu

Harry B. Gray-Division of Chemistry and Chemical Engineering, California Institute of Technology, 1200 East California Boulevard, Pasadena, CA 91125 orcid.org/0000-0002-7937-7876

Email:hbgray@caltech.edu

\section{Authors}

Julia M. Stauber - Department of Chemistry and Biochemistry, University of California, Los Angeles, 607 Charles E. Young Dr. E., Los Angeles, CA 90095 orcid.org/0000-0001-9783-907X

Josef Schwan - Division of Chemistry and Chemical Engineering, California Institute of Technology, 1200 East California Boulevard, Pasadena, CA 91125

Xinglong Zhang - Division of Chemistry and Chemical Engineering, California Institute of Technology, 1200 East California Boulevard, Pasadena, CA 91125 orcid.org/0000-0003-1698-692X

Jonathan C. Axtell ${ }^{\dagger}$ - Department of Chemistry and Biochemistry, University of California, Los Angeles, 607 Charles E. Young Dr. E., Los Angeles, CA 90095 orcid.org/0000-0002-5579-4296

Dahee Jung - Department of Chemistry and Biochemistry, University of California, Los Angeles, 607 Charles E. Young Dr. E., Los Angeles, CA 90095 orcid.org/0000-0003-1863-0193

Brendon J. McNicholas - Division of Chemistry and Chemical Engineering, California Institute of Technology, 1200 East California Boulevard, Pasadena, CA 91125

orcid.org/0000-0002-3654-681X

Paul H. Oyala - Division of Chemistry and Chemical Engineering, California Institute of Technology, 1200 East California Boulevard, Pasadena, CA 91125 orcid.org/0000-0002-8761-4667

Andrew J. Martinolich - Division of Chemistry and Chemical Engineering, California Institute of Technology, 1200 East California Boulevard, Pasadena, CA 91125 orcid.org/0000-0002-7866-9594
Jay R. Winkler - Division of Chemistry and Chemical Engineering, California Institute of Technology, 1200 East California Boulevard, Pasadena, CA 91125 orcid.org/0000-0002-4453-9716

Kimberly A. See - Division of Chemistry and Chemical Engineering, California Institute of Technology, 1200 East California Boulevard, Pasadena, CA 91125 orcid.org/0000-0002-0133-9693

\section{Present Addresses}

$\dagger$ The Dow Chemical Company, 633 Washington St., Midland, MI, 48674

\section{Notes}

UCLA has patents on several compounds reported in this work from which A.M.S. and current/former co-workers may receive royalty payments. The $\mathrm{Cs}_{2}\left[\mathrm{~B}_{12}(\mathrm{OH})_{12}\right]$ salt (Catalog \#902209) is commercially available through the MilliporeSigma catalog.

\section{ACKNOWLEDGMENT}

This work was supported as part of the Center for Synthetic Control Across Length-scales for Advancing Rechargeables (SCALAR), an Energy Frontier Research Center funded by the U.S. Department of Energy (DOE), Office of Science, Basic Energy Sciences (BES) under Award \# DE-SC0019381 (A. M. S. and K. A. S. synthesis and characterization; T. F. M., computational work and theory). A. M. S. is a Research Corporation for Science Advancement (RCSA) Cottrell Scholar and a Dreyfus Foundation Camille Dreyfus Teacher-Scholar. Acknowledgment is made to the donors of The American Chemical Society Petroleum Research Fund for funding work in the H. B. G. lab (J.S. and H. B. G.). Work in the Beckman Institute at Caltech was supported by the Arnold and Mabel Beckman Foundation (B. J. M., J. R. W.). X. Z. acknowledges the Agency for Science, Technology and Research (Singapore) for an A*STAR fellowship. X. Z. and T. F. M. acknowledge the computational resources from the Extreme Science and Engineering Discovery Environment (XSEDE) Bridges computer at the Pittsburgh Supercomputing Center through allocation TGMCB160013. A. J. M. acknowledges support through a postdoctoral fellowship from the Resnick Sustainability Institute at Caltech. D. J. acknowledges the UCLA Graduate Division for the Dissertation Year Fellowship. The National Science Foundation (NSF-1531940) and the Dow Next Generation Educator Fund are acknowledged for EPR facility support.

\section{REFERENCES}

(1) Hawthorne, M. F.; Pushechnikov, A. Polyhedral Borane Derivatives: Unique and Versatile Structural Motifs. Pure Appl. Chem. 2012, 84 (11), 2279-2288.

(2) Axtell, J. C.; Saleh, L. M. A.; Qian, E. A.; Wixtrom, A. I.; Spokoyny, A. M. Synthesis and Applications of Perfunctionalized Boron Clusters. Inorg. Chem. 2018, 57 (5), 2333-2350.

(3) Leśnikowski, Z. J. Challenges and Opportunities for the Application of Boron Clusters in Drug Design. J. Med. Chem. 2016, 59 (17), 7738-7758.

(4) Dash, B. P.; Satapathy, R.; Maguire, J. A.; Hosmane, N. S. Polyhedral Boron Clusters in Materials Science. New J. Chem. 2011, 35 (10), 1955-1972.

(5) Grimes, R. N. Boron Clusters Come of Age. J. Chem. Educ. 2004, 81 (5), 657-672.

(6) Onak, T. Polyhedral Carbaboranes. Comprehensive Organometallic Chemistry II 1995, 217-255.

(7) Boron Science New Technologies and Applications, 1st ed.; Hosmane, N. S., Ed.; Taylor \& Francis Group, LLC: Boca Raton, 2012.

(8) Handbook of Boron Science: With Applications in 
Organometallics, Catalysis, Materials and Medicine; Narayan S Hosmane, R. E., Ed.; World Scientific Publishing Europe Ltd.: London, 2019.

(9) Hosmane, N. S.; Maguire, J. A.; Yinghuai, Z. Polyhedral Boron Cage Compounds: An Account. Main Group Chemistry 2006, 5 (4), 251-265.

(10) Polyhedral Carboranes. In Comprehensive Organometallic Chemistry III; Crabtree, R. H., Mingos, D. M. P., Eds.; Elsevier, 2007.

(11) Pitochelli, A. R.; Hawthorne, F. M. The Isolation of the Icosahedral B12H12-2 Ion. J. Am. Chem. Soc. 1960, 82 (12), 3228-3229.

(12) Farha, O. K.; Julius, R. L.; Lee, M. W.; Huertas, R. E.; Knobler, C. B.; Hawthorne, M. F. Synthesis of Stable Dodecaalkoxy Derivatives of Hypercloso- $\mathrm{B}_{12} \mathrm{H}_{12}$. J. Am. Chem. Soc. 2005, 127 (51), 18243-18251.

(13) Wiersema, R. J.; Middaugh, R. L. Electrochemical Preparation and Halogenation of 1,1'- $\mu$-Hydro-Bis(Undecahydro-ClosoDodecaborate)(3-), $\mathrm{B}_{24} \mathrm{H}_{23}{ }^{3-}$. Inorg. Chem. 1969, 8 (10), 2074 2079.

(14) Wade, K. The Structural Significance of the Number of Skeletal Bonding Electron-Pairs in Carboranes, the Higher Boranes and Borane Anions, and Various Transition-Metal Carbonyl Cluster Compounds. J. Chem. Soc. D Chem. Commun. 1971, No. 15, 792-793.

(15) Mingos, D. M. P. Polyhedral Skeletal Electron Pair Approach. Acc. Chem. Res. 1984, 17 (9), 311-319.

(16) Boeré, R. T.; Kacprzak, S.; Keßler, M.; Knapp, C.; Riebau, R.; Riedel, S.; Roemmele, T. L.; Rühle, M.; Scherer, H.; Weber, S. Oxidation of Closo- $\left[\mathrm{B}_{12} \mathrm{Cl}_{12}\right]^{2-}$ to the Radical Anion $\left[\mathrm{B}_{12} \mathrm{Cl}_{12}\right]^{\text {- }}$ and to Neutral $\mathrm{B}_{12} \mathrm{Cl}_{12}$. Angew. Chem. Int. Ed. 2011, 50 (2), 549-552.

(17) Kaim, W.; Hosmane, N. S.; Záliš, S.; Maguire, J. A.; Lipscomb, W. N. Boron Atoms as Spin Carriers in Two- and ThreeDimensional Systems. Angew. Chem. - Int. Ed. 2009, 48 (28), 5082-5091.

(18) Peymann, T.; Knobler, C. B.; Hawthorne, M. F. An Unpaired Electron Incarcerated within an Icosahedral Borane Cage: Synthesis and Crystal Structure of the Blue, Air-Stable \{[Closo$\left.\left.\mathrm{B}_{12}\left(\mathrm{CH}_{3}\right)_{12}\right]^{*}\right\}$-Radical. Chem. Commun. 1999, 12 (20), 20392040.

(19) Van, N.; Tiritiris, I.; Winter, R. F.; Sarkar, B.; Singh, P.; Duboc C.; Muñoz-Castro, A.; Arratia-Pérez, R.; Kaim, W.; Schleid, T. Oxidative Perhydroxylation of $\left[\text { Closo- } \mathrm{B}_{12} \mathrm{H}_{12}\right]^{2-}$ to the Stable Inorganic Cluster Redox System $\left[\mathrm{B}_{12}(\mathrm{OH})_{12}\right]^{2-\%}$ : Experiment and Theory. Chem. - A Eur. J. 2010, 16 (37), 11242-11245.

(20) Lee, M. W.; Farha, O. K.; Hawthorne, M. F.; Hansch, C. H. Alkoxy Derivatives of Dodecaborate: Discrete Nanomolecular Ions with Tunable Pseudometallic Properties. Angew. Chem. Int. Ed. 2007, 46 (17), 3018-3022.

(21) Barton, J. L.; Wixtrom, A. I.; Kowalski, J. A.; Qian, E. A.; Jung, D.; Brushett, F. R.; Spokoyny, A. M. Perfunctionalized Dodecaborate Clusters as Stable Metal-Free Active Materials for Charge Storage. ACS Appl. Energy Mater. 2019, 2, 4907-4913.

(22) Aubry, T. J.; Axtell, J. C.; Basile, V. M.; Winchell, K. J.; Lindemuth, J. R.; Porter, T. M.; Liu, J. Y.; Alexandrova, A. N.; Kubiak, C. P.; Tolbert, S. H.; Spokoyny, A. M.; Schwartz, B. J. Dodecaborane-Based Dopants Designed to Shield Anion Electrostatics Lead to Increased Carrier Mobility in a Doped Conjugated Polymer. Adv. Mater. 2019, 31 (11), 1-8.

(23) Jung, D.; Saleh, L. M. A.; Berkson, Z. J.; El-Kady, M. F.; Hwang, J. Y.; Mohamed, N.; Wixtrom, A. I.; Titarenko, E.; Shao, Y.; McCarthy, K.; Guo, J.; Martini, I. B.; Kraemer, S.; Wegener, E. C.; Saint-Cricq, P.; Ruehle, B.; Langeslay, R. R.; Delferro, M.; Brosmer, J. L.; Hendon, C. H.; Gallagher-Jones, M.; Rodriguez, J.; Chapman, K. W.; Miller, J. T.; Duan, X.; Kaner, R. B.; Zink, J. I.; Chmelka, B. F.; Spokoyny, A. M. A Molecular Cross-Linking Approach for Hybrid Metal Oxides. Nat. Mater. 2018, 17 (4), 341-348.

(24) Wixtrom, A. I.; Shao, Y.; Jung, D.; Machan, C. W.; Kevork, S. N.; Qian, E. A.; Axtell, J. C.; Khan, S. I.; Kubiak, C. P.; Spokoyny, A. M. Rapid Synthesis of Redox-Active Dodecaborane B12(OR)12 Clusters Under Ambient Conditions. Inorg. Chem. Front. 2016, 3, 711-717.

(25) Wixtrom, A. I.; Parvez, Z. A.; Savage, M. D.; Qian, E. A.; Jung,
D.; Khan, S. I.; Rheingold, A. L.; Spokoyny, A. M. Tuning the Electrochemical Potential of Perfunctionalized Dodecaborate Clusters through Vertex Differentiation. Chem. Commun. 2018, 54 (46), 5867-5870

(26) Muetterties, E. L.; Balthis, J. H.; Chia, Y. T.; Knoth, W. H.; Miller, H. C. Chemistry of Boranes. VIII. Salts and Acids of $\mathrm{B}_{10} \mathrm{H}_{10}{ }^{-2}$ and $\mathrm{B}_{12} \mathrm{H}_{12}{ }^{-2}$. Inorg. Chem. 1964, 3 (3), 444-451.

(27) Sivaev, I. B.; Bregadze, V. I.; Sjöberg, S. Chemistry of ClosoDodecaborate Anion $\left[\mathrm{B}_{12} \mathrm{H}_{12}\right]^{2-:}$ : A Review. Collect. Czechoslov. Chem. Commun. 2002, 67 (6), 679-727.

(28) Rupich, M. W. Characterization of Chloroclosoborane Acids as Electrolytes for Acid Fuel Cells. J. Electrochem. Soc. 1985, 132 (1), 119-122.

(29) Bard, A. J.; Faulkner, L. R. Electrochemical Methods, 2nd ed.; John Wiley \& Sons, 2001

(30) McNicholas, B. J.; Grubbs, R. H.; Winkler, J. R.; Gray, H. B.; Despagnet-Ayoub, E. Tuning the Formal Potential of Ferrocyanide over a $2.1 \mathrm{~V}$ Range. Chem. Sci. 2019, 10 (12), 3623-3626.

(31) Steckhan, E.; Schmidt, W. Elektrochemische Und Spektroskopische Untersuchung Bromsubstituierter Triarylamin-Redoxsysteme. Chem. Ber. 1980, 113, 577-585.

(32) Connelly, N. G.; Geiger, W. E. Chemical Redox Agents for Organometallic Chemistry. Chem. Rev. 1996, 96 (2), 877-910.

(33) King, B. T.; Noll, B. C.; McKinley, A. J.; Michl, J. Dodecamethylcarba-Closo-Dodecaboranyl $\left(\mathrm{CB}_{11} \mathrm{Me}_{12}\right)$, a Stable Free Radical. J. Am. Chem. Soc. 1996, 118 (44), 10902-10903.

(34) King, B. T.; Michl, J. The Explosive "Inert" Anion $\mathrm{CB}_{11}\left(\mathrm{CF}_{3}\right)_{12}$ J. Am. Chem. Soc. 2000, 122 (41), 10255-10256.

(35) Chiu, C. W.; Gabbaï, F. P. A 9-Borylated Acridinyl Radical. Angew. Chem. - Int. Ed. 2007, 46 (10), 1723-1725.

(36) Liu, L.; Cao, L. L.; Shao, Y.; Ménard, G.; Stephan, D. W. A Radical Mechanism for Frustrated Lewis Pair Reactivity. Chem 2017, 3 (2), 259-267.

(37) Eisenberg, R.; Gray, H. B. Noninnocence in Metal Complexes: A Dithiolene Dawn. Inorg. Chem. 2011, 50 (20), 9741-9751.

(38) Malischewski, M.; Adelhardt, M.; Sutter, J.; Meyer, K.; Seppelt, $\mathrm{K}$. Isolation and Structural and Electronic Characterization of Salts of the Decamethylferrocene Dication. Science 2016, 353 (6300), 678-682.

(39) Evans, W. J. Tutorial on the Role of Cyclopentadienyl Ligands in the Discovery of Molecular Complexes of the Rare-Earth and Actinide Metals in New Oxidation States. Organometallics 2016, 35 (18), 3088-3100.

(40) Soleilhavoup, M.; Bertrand, G. Cyclic (Alkyl)(Amino)Carbenes (CAACs): Stable Carbenes on the Rise. Acc. Chem. Res. 2015, 48 (2), 256-266.

(41) Fisher, S. P.; Tomich, A. W.; Lovera, S. O.; Kleinsasser, J. F.; Guo, J.; Asay, M. J.; Nelson, H. M.; Lavallo, V. Nonclassical Applications of Closo-Carborane Anions: From Main Group Chemistry and Catalysis to Energy Storage. Chem. Rev. 2019, 119, 8262-8290.

(42) Wolczanski, P. T. Flipping the Oxidation State Formalism: Charge Distribution in Organometallic Complexes As Reported by Carbon Monoxide. Organometallics 2017, 36 (3), 622-631.

(43) Power, P. P. Persistent and Stable Radicals of the Heavier Main Group Elements and Related Species. Chem. Rev. 2003, 103 (3), 789-809.

(44) Légaré, M. A.; Pranckevicius, C.; Braunschweig, H. Metallomimetic Chemistry of Boron. Chem. Rev. 2019, 119, 8231-8261.

(45) Martin, C. D.; Soleilhavoup, M.; Bertrand, G. CarbeneStabilized Main Group Radicals and Radical Ions. Chem. Sci. 2013, 4 (8), 3020-3030. 


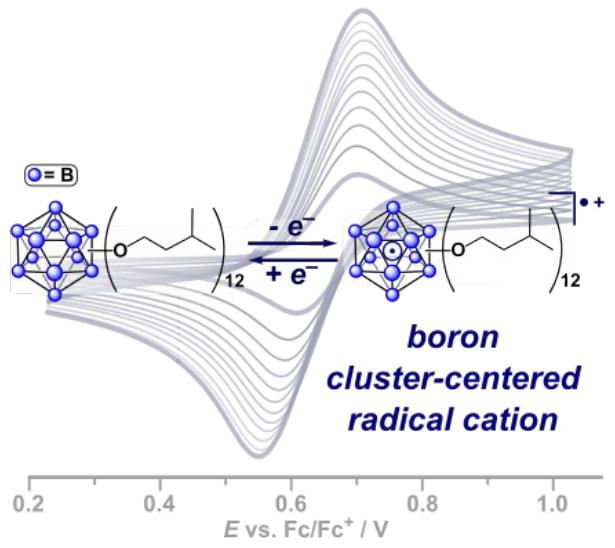

For Table of Contents Entry Only 


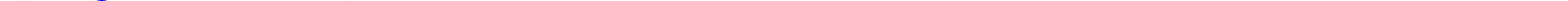

